\title{
Analisis Video Share to Video Comments Ratio TikTok Pada 5 Akun Tutorial Memasak
}

\author{
I Putu Dharma Kusala \\ dhrmkusala@gmail.com
}

\begin{abstract}
There are so many social media platforms that can be used as a means of communication in the 4.0 era, from Facebook, Twitter, Instagram to TikTok. TikTok is a social media platform from China that allows users to create 15 -second videos accompanied by music, filters, and other creative features. In 2021 TikTok will become one of the most popular social media platforms worldwide. In Indonesia alone TikTok has been downloaded by 30.7 million Indonesians. Seeing the large number of Tiktok users in Indonesia, people are starting to try to take advantage of the TikTok social media platform to gain fame or even share useful knowledge such as easy and fun cooking tutorials. There are 5 tiktok accounts about cooking tutorials that are in great demand by the Indonesian people, including: querrkunoichi, garciandyyy, yackikuka, makfoodies, felya_ng. This research is expected to determine the credibility of the performance of 5 TikTok cooking tutorial accounts using quantitative exploratory methods. The results obtained from this study indicate that the TikTok makfoodies account occupies the highest rank and has good account credibility.
\end{abstract}

\section{ABSTRAK}

Banyak sekali platform sosial media yang dapat digunakan sebagai saranan komunikasi di era 4.0, mulai dari Facebook, Twitter, Instagram sampai dengan TikTok. TikTok merupakan platform media sosial asal Tiongkok yang memungkinkan penggunanya membuat video berdurasi 15 detik yang disertai dengan musik, filter, dan beberapa fitur kreatif lainnya. Pada tahun 2021 TikTok menjadi salah satu platform media sosial yang digemari di seluruh dunia. Di Indonesia sendiri TikTok telah diunduh oleh 30,7 juta masyarakat Indonesia. Melihat banyaknya pengguna Tiktok di Indonesia, masyarakat mulai berusaha memanfaatkan platform media sosial TikTok dengan untuk meraih ketenaran atau bahkan sekedar berbagi ilmu yang bermanfaat seperti tutorial memasak yang mudah dan seru. Adapun 5 akun tiktok tentang tutorial memasak yang banyak diminati oleh masyarakat Indonesia, diantaranya : querrkunoichi, garciandyyy, yackikuka, makfoodies, felya_ng. Penelitian ini diharapkan dapat mengetahui kredibilitas dari performa 5 akun TikTok tutorial memasak dengan menggunakan metode eksploratif kuantitatif. Hasil yang didapat dari penelitian ini menunjukan bahwa akun TikTok makfoodies menduduki peringkat tertinggi serta memiliki kredibilitas akun yang baik.

Keyword : Credibility Account TikTok ; Social Media Marketing ; Social Media TikTok ; Video Shares to Video Comments Ratio ; Akun Tutorial Memasak 


\section{PENDAHULUAN}

Perkembangan teknologi terus berkembang seiring berjalannya waktu, hal ini membawa banyak dampak positif terhadap keberlangsungan hidup manusia di era 4.0 ini. Salah satunya adalah perkembangan sistem tenologi informasi komunikasi, dari yang awalnya hanya bergantung pada pesawat telfon sekarang digantikan oleh adanya media sosial. Saat ini media sosial digunakan sebagai sarana komunikasi oleh berbagai kalangan masyarakat karena dipandang memiliki beragam fitur yang menarik dan kemudahan dalam menggunakannya.

Banyak sekali platform sosial media yang dapat digunakan sebagai saranan komunikasi di era 4.0, mulai dari Facebook, Twitter, Instagram sampai dengan TikTok. TikTok merupakan platform media sosial asal Tiongkok yang memungkinkan penggunanya membuat video berdurasi 15 detik yang disertai dengan musik, filter, dan beberapa fitur kreatif lainnya(Adawiyah, 2020)

Pada tahun 2021 TikTok menjadi salah satu platform media sosial yang digemari di seluruh dunia. Di Indonesia sendiri TikTok telah diunduh oleh 30,7 juta masyarakat Indonesia. Melihat banyaknya pengguna Tiktok di Indonesia, masyarakat mulai berusaha memanfaatkan platform media sosial TikTok dengan untuk meraih ketenaran atau bahkan sekedar berbagi ilmu yang bermanfaat seperti tutorial memasak yang mudah dan seru. penelitian ini akan menggunakan metode eksploratif kuantitatif, dan akan menghitung menggunakan rasio-rasio yang ada pada TikTok. Pada penelitian (I Putu Hendika Permana \& Ni Putu Suci Meinarni, 2021)menjelaskan bahwa terdapat 17 rasio yang ada pada sosial media TikTok dan relevan digunakan sebagai media ukur kredibilitas akun yang ada. Penelitian ini hanya berfokus untuk menghitung kredibilitas Video Comments to Video Shares Ratio pada 5 akun TikTok tutorial memasak di Indonesia. Tujuan dari penelitian ini adalah mengetahui kredibilitas performa dari 5 akun TikTok tutorial memasak di Indonesia menggunakan Video Comments to Video Shares Ratio.

\section{TINJAUAN PUSTAKA}

Indonesia sebagai negara maju memiliki presentase penggunaa internet terbesar peringkat ke-enam di dunia. Pengguna internet di Indonesia pada awal tahun 2021 tercatat mencapai 202,6 juta jiwa, jumlah ini meningkat 15,5 persen atau 27 juta jiwa jika dibandingkan pada Januari 2020 lalu. Total jumlah penduduk Indonesia sendiri saat ini adalah 274,9 juta jiwa. Jadi dapat di kalkulasikan bahwa presentase internet di Indonesia pada awal 2021 mencapai 73,7 persen. (Kompas, 2021)

Salah satu platform media sosial yang mengalami peningkatan pengguna di Indonesia adalah TikTok. Sebenarnya TikTok bukan sebuah platform media social baru, TikTok mulai di kenal di Indonesia sekitar tahun 2018-2019. Namun karena kominfo sempat melakukan pemblokiran karena menganggap TikTok memproduksi konten negatif, terutama bagi kalangan anak-anak. (daon001, 2018)

Namum pada tahun 2021 kominfo mencabut blokir pada aplikasi ini. Hal ini menyebabkan banyak masyarakat Indonesia yang Kembali menggunakan TikTok, Karena TikTok menghadirkan banyak fitur-fitur yang menarik untuk dicoba. Salah satu fitur yang menarik adalah hadir nya FYP (For Your Page) yang menungkinkan video yang dibuat oleh 
seseorang user muncul di beranda user lain. Semenjak FYP dihadirkan banyak pengguna TikTok yang memanfaatkan fitur tersebut dalam mencari kepopuleran, baik dengan membuat video hiburan atau bahkan video edukasi. Kredibilitas kepopuleran suatu akun TikTok dapat diukur melalui pengukuran yang terhubung dengan rasio.

\section{METODOLOGI PENELITIAN}

Untuk mengetahui kredibilitas dari peforma 5 akun TikTok tutorial memasak, peneliti menerapkan metode eksploratif kuantitatif sebagai acuan penelitian. Penelitian eksploratif merupakan sebuah penelitian yang memberikan definisi perihal suatu konsep dengan cara melakukan eksplorasi mengenai suatu hal tertentu. Penelitian ini bersifat lebih fleksibel, kreatif, terbuka, dan semua sumber dianggap penting sebagai sumber informasi.

Penelitian ini diharapkan dapat mengetahui kredibilitas dari peforma 5 akun TikTok tutorial memasak, membuka kemungkinan untuk melakukan penelitian lanjutan terhadap topik sebelumnya, serta menentukan tehnik dan arah pada penelitian selanjutnya. (Penelitian Eksploratif, 2021)Terdapat langkah-langkah yang harus dilakukan untuk mengetahui kredibilitas dari objek yang digunakan, yaitu:

1. Melakukan Eksplorasi Pada Website Untuk Menentukan Objek yang Akan Dianalisa. Langkah pertama adalah melakukan eksplorasi terhadap beberapa website yang memuat informasi mengenai objek-objek yang akan menjadi bahan penelitian. Dalam penelitian ini menggunakan objek akun-akun TikTok tutorial memasak. Setelah mendapatkan informasi, hal yang dilakukan selanjutnya adalah memastikan setiap objek memiliki akun pada platform media sosial TikTok.

2. Menghitung Nilai Rata-Rata Variable Dari 5 Akun TikTok Tutorial Memasak. Langkah kedua adalah menghitung variable video comments dan variable video shares. Variabel yang digunakan mencakup segala informasi dari objek yang akan diteliti untuk mendapatkan informasi untuk menarik sebuah kesimpulan. Untuk mendapatkan nilai rata-rata dari variable video comments dan variable video shares digunakan 10 sample video dari postingan setiap akun, yang kemudian dihitung dan akan menghasilkan nilai rata-rata dari setiap variabel.

3. Menghitung Nilai Kredibilitas Rasio

Pada Langkah ini peneliti menghitung nilai kredibilitas video comments to video shares dengan cara membagi nilai variabel pertama dengan variabel kedua. Jika video commenys bernilai 100 dan video shares bernilai 300. Maka kedua nilai tersebut akan dibagi dan hasil yang didapat digunakan sebagai acuan.

\section{Menentukan Peringkat Pada Akun TikTok}

Langkah terakhir adalah menentukan peringkan untuk setiap rasio dari semua objek. Penentuan peringkat harus selaras dengan rasio yang diteliti. Jika rasio memiliki karakteristik rendah objek dengan nilai terendah akan berada pada peringkat 5 dan objek dengan nilai tertinggi akan berada pada peringkat 1. Bila rasio memiliki 
karakteristik tinggi objek dengan nilai tertinggi berada pada peringkat 5 dan objek dengan nilai terendah akan berada pada peringkat 1 .

\section{HASIL DAN PEMBAHASAN}

Akun TikTok dari 5 Akun Tutorial Memasak, diantaranya:

1. querrkunoichi
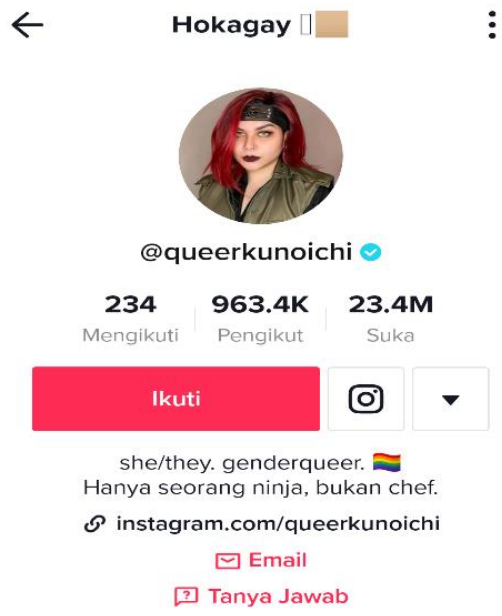

Gambar 1 Akun TikTok querrkunoichi

Sumber: https://vt.tiktok.com/ZSeFVX3BH/ (akses pada 12-10-2021)

\section{2. garciandyyy}

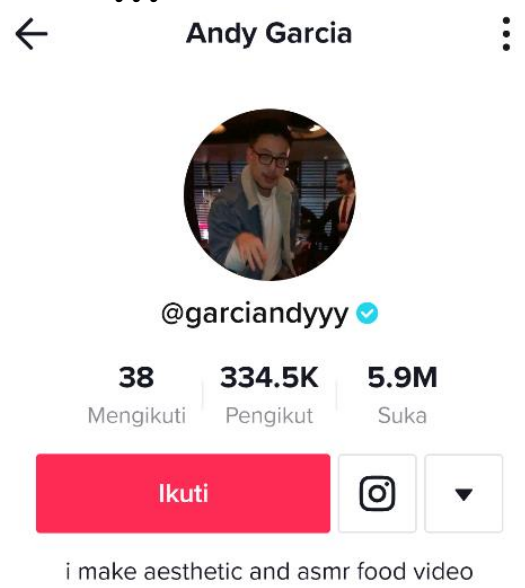

?. Tanya Jawab

Gambar 2 Akun TikTok garciandyyy

Sumber: https://vt.tiktok.com/ZSeFVwojh/ (akses pada 12-10-2021) 
3. yackikuka

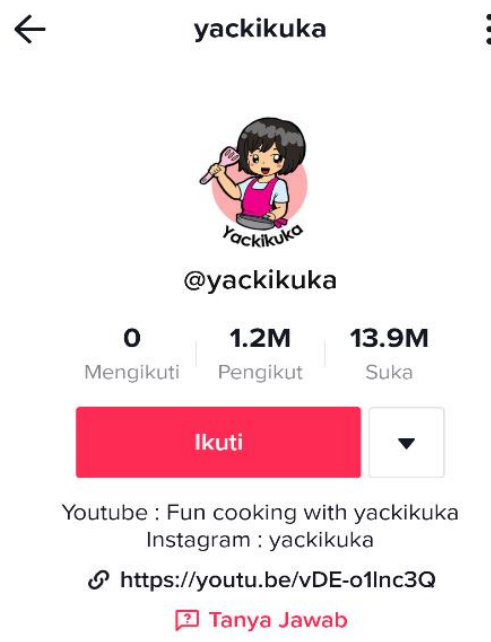

Gambar 3 Akun TikTok yackikuka

Sumber: https://vt.tiktok.com/ZSeFVpQ6t/ (akses pada 12-10-2021)

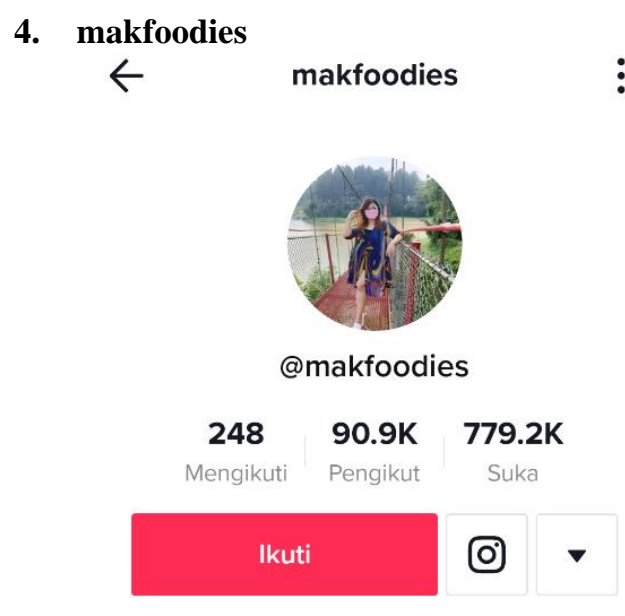

GAES BANTU LIKE \& SUBSCRIBE YA

$\mathcal{O}$ https://www.youtube.com/channe...

Gambar 4 Akun TikTok makfoodies

Sumber: https://vt.tiktok.com/ZSeFVncwb/ (akses pada 12-10-2021) 


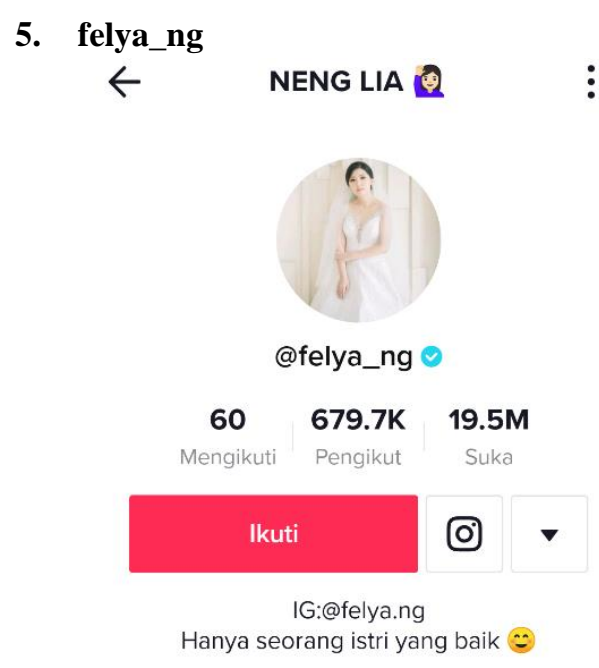

Gambar 5 Akun TikTok felya_ng

Sumber: https://vt.tiktok.com/ZSeFVG3T1/ (akses pada 12-10-2021)

Dari kelima akun TikTok dari 5 Akun Tutorial Memasak, peneliti menemukan nilai dari masing-masing variable yang ada untuk menghitung rasio Video Shares to Video Comment dari setiap akun. Pada akun TikTok terdapat 7 variabel, diantaranya yaitu :

1. Likes

2. Followers

3. Following

4. Video Likes

5. Video Comments

6. Video Share

7. Video Views

Dari ketujuh variable tersebut peneliti hanya focus untuk menemukan hasil dari 2 variabel, yaitu:

1. Video Shares

2. Video Comment

Dari kedua variable tersebut kemudian dianalisa sehingga menemukan nilai rata-rata dari variable video shares dan video comments. Untuk menghitung rata-rata dari variable video shares dan video comments yaitu dengan cara mengambil mininal 10 postingan kemudian dihitung sehingga menemukan nilai rata-rata dari masing-masing variable. Berikut merupakan tabel nilai rata-rata dari masing-masing skincare lokal terbaik tahun 2021, yaitu:

Tabel 1. Analisa Nilai Rata-Rata Nilai Variabel Video Shares to Video Comment Akun TikTok querrkunoichi 


\begin{tabular}{|c|c|c|}
\hline No & Video Likes & Video Views \\
\hline 1 & 200 & 353 \\
\hline 2 & 785 & 583 \\
\hline 3 & 62 & 83 \\
\hline 4 & 44 & 157 \\
\hline 5 & 112 & 111 \\
\hline 6 & 19 & 114 \\
\hline 7 & 29 & 152 \\
\hline 8 & 21 & 73 \\
\hline 9 & 1,521 & 543 \\
\hline 10 & 13 & 42 \\
\hline Total & 281 & 221 \\
\hline
\end{tabular}

Sumber: Pengolah Data Excel

Tabel 2. Analisa Nilai Rata-Rata Nilai Variabel Video Shares to Video Comment Akun TikTok garciandyyy

\begin{tabular}{|c|c|c|}
\hline No & Video Likes & Video Views \\
\hline 1 & 349 & 98 \\
\hline 2 & 20 & 5 \\
\hline 3 & 265 & 68 \\
\hline 4 & 22 & 13 \\
\hline 5 & 160 & 34 \\
\hline 6 & 49 & 13 \\
\hline 7 & 129 & 37 \\
\hline 8 & 42 & 9 \\
\hline 9 & 101 & 35 \\
\hline 10 & 216 & 21 \\
\hline Total & 135 & 33 \\
\hline
\end{tabular}

Sumber: Pengolah Data Excel 
Tabel 3. Analisa Nilai Rata-Rata Nilai Variabel Video Shares to Video Comment Akun TikTok yackikuka

\begin{tabular}{|c|c|c|}
\hline No & Video Likes & Video Views \\
\hline 1 & 70 & 2 \\
\hline 2 & 162 & 11 \\
\hline 3 & 22 & 27 \\
\hline 4 & 12 & 19 \\
\hline 5 & 21 & 16 \\
\hline 6 & 190 & 13 \\
\hline 7 & 38 & 17 \\
\hline 8 & 13 & 11 \\
\hline 9 & 9 & 14 \\
\hline 10 & 8 & 34 \\
\hline Total & 55 & 16 \\
\hline
\end{tabular}

Sumber: Pengolah Data Exccel

Tabel 4. Analisa Nilai Rata-Rata Nilai Variabel Video Shares to Video Comment Akun TikTok makfoodies

\begin{tabular}{|c|c|c|}
\hline No & Video Likes & Video Views \\
\hline 1 & 1,882 & 1,075 \\
\hline 2 & 4,808 & 1,341 \\
\hline 3 & 4,139 & 685 \\
\hline 4 & 15 & 2 \\
\hline 5 & 330 & 10 \\
\hline 6 & 3 & 6 \\
\hline 7 & 10 & 2 \\
\hline 8 & 10 & 3 \\
\hline 9 & 23 & 2 \\
\hline 10 & 19 & 4 \\
\hline Total & 1,124 & 313 \\
\hline
\end{tabular}

Sumber: Pengolah Data Excel 
Tabel 5. Analisa Nilai Rata-Rata Nilai Variabel Video Shares to Video Comment Akun TikTok felya_ng

\begin{tabular}{|c|c|c|}
\hline No & Video Likes & Video Views \\
\hline 1 & 13 & 8 \\
\hline 2 & 2 & 5 \\
\hline 3 & 15 & 7 \\
\hline 4 & 13 & 12 \\
\hline 5 & 65 & 31 \\
\hline 6 & 12 & 9 \\
\hline 7 & 18 & 9 \\
\hline 8 & 61 & 37 \\
\hline 9 & 29 & 6 \\
\hline 10 & 17 & 5 \\
\hline Total & 25 & 13 \\
\hline
\end{tabular}

Sumber: Pengolah Data Excel

Setelah menghitung nilai rata-rata tersebut, maka akan menemukan hasil akhir nilai ratarata dari variable Video Shares to Video Comment.

Tabel 6. Nilai Variabel Pada Akun TikTok dari 5 Akun Tutorial Memasak.

\begin{tabular}{|c|c|c|c|c|c|}
\hline Variable & querrkunoichi & garciandyyy & yackikuka & makfoodies & felya_ng \\
\hline Video Share & 281 & 135 & 55 & 1,124 & 25 \\
\hline $\begin{array}{c}\text { Video } \\
\text { Comment }\end{array}$ & 221 & 33 & 16 & 33 & 13 \\
\hline
\end{tabular}

\section{Sumber: Pengolah Data Excel}

Pada akun TikTok terdapat 17 rasio yang relevan digunakan untuk mengukur kredibilitas pada masing-masing akun. Namun pada penelitian kali ini hanya berfokus untuk menghitung Video Shares to Video Comment. Untuk menghitung kredibilitas dari masingmasing akun TikTok setiap akun, peneliti menghitung dengan cara : variabel 1 akan dibagi dengan variabel 2, sehingga ditemukan hasil analisisa dari rasio tersebut.

Tabel 7. Hasil Perhitungan Rasio Akun TikTok

\begin{tabular}{|c|l|c|c|c|c|c|}
\hline $\begin{array}{c}\mathrm{N} \\
\mathrm{o}\end{array}$ & \multicolumn{1}{|c|}{ Ratio } & $\begin{array}{c}\text { querkunoich } \\
\mathrm{i}\end{array}$ & garciandyyy & $\begin{array}{c}\text { yackikuk } \\
\mathrm{a}\end{array}$ & makfoodies & felya_ng \\
\hline 1 & Video & 1.271493213 & 4.09090909 & 3.4375 & 34.0606060 & 1.92307692 \\
& $\begin{array}{l}\text { Share to } \\
\text { Video } \\
\text { Commen } \\
\text { t Ratio }\end{array}$ & & 1 & & 6 & 3 \\
\hline
\end{tabular}

Sumber: Pengolah Data Excel 
Video Shares to Video Comment memiliki karakteristik yang tinggi, artinya semakin tinggi nilai yang dihasilkan maka semakin baik kredibilitas dari performa akun tersebut. Untuk memberikan peringkat pada masing-masing Akun, peneliti memberikan angka 5 kepada akun yang mendapat nilai tertinggi dan angka 1 untuk akun yang mendapatkan nilai terendah. Berikut merupakan tabel urutan nilai yang dihasilkan oleh masing-masing akun.

Tabel 8. Nilai Rasio Akun TikTok dari 5 Akun Tutorial Memasak

\begin{tabular}{|l|c|c|c|c|c|}
\hline \multirow{2}{*}{ RATIO } & \multicolumn{5}{|c|}{ NILAI } \\
\cline { 2 - 6 } & querrkunoichi & garciandyyy & yackikuka & makfoodies & felya_ng \\
\hline Video & 1 & 4 & 3 & 5 & 2 \\
Shares to & & & & & \\
Video & & & & & \\
Comment & & & & & \\
\hline
\end{tabular}

Sumber: Pengolah Data Excel

Dari Tabel Nilai Rasio Akun TikTok dari 5 Akun Tutorial Memasak dapat disimpulkan bahwa makfoodies mendapatkan nilai tertinggi untuk rasio Video Shares to Video Comment. Sedangkan akun TikTok querrkunoichi mendapatkan nilai terendah untuk rasio ini. Jadi, pada penelitian ini makfoodies memiliki kredibilitas performa yang lebih baik dibandingkan dengan akun yang lainnya.

\section{KESIMPULAN}

Tujuan dari penelitian ini adalah mengetahui kredibilitas performa Akun TikTok dari 5 Akun Tutorial Memasak menggunakan Video Shares to Video Comment. 5 Akun Tutorial Memasak tersebut diantaranya: querrkunoichi, garciandyyy, yackikuka, makfoodies, dan felya_ng. Dari kelima akun tersebut dapat disimpulkan bahwa:

1. Peringkat pertama diraih oleh akun makfoodies dengan nilai tertinggi yaitu 34,06060606

2. Peringkat kedua diraih oleh akun garciandyyy dengan nilai 4,090909091

3. Peringkat ketiga diraih oleh akun yackikuka dengan nilai 3,4375

4. Peringkat keempat diarih oleh akun felya_ng dengan nilai 1,923076923

5. Peringkat kelima diraih oleh akun querrkunoichi dengan nilai terendah yaitu 1,271493213 


\section{DAFTAR PUSTAKA}

Adawiyah, D. P. R. (2020). Pengaruh Penggunaan Aplikasi TikTok Terhadap Kepercayaan Diri Remaja di Kabupaten Sampang. Jurnal Komunikasi, 14(2), 135-148.

https://doi.org/10.21107/ilkom.v14i2.7504

daon001. (2018, July 4). Ini Penyebab Kominfo Putuskan Blokir Tik Tok. Www.Kompas.Com.

I Putu Hendika Permana, \& Ni Putu Suci Meinarni. (2021). Ratio Analysis on Tiktok (Social Media) for Qualitative Research Using Explorative Methods. Jurnal Ekonomi \& Bisnis JAGADITHA, 8(1), 30-38. https://doi.org/10.22225/jj.8.1.2944.30-38

Kompas. (2021, February 23). Jumlah Pengguna Internet Di Indonesia. Www.Kompas.Com.

Penelitian eksploratif. (2021, May 18). Www.Wikipedia.Org. 